of slight giddiness, became rery fiogettr, and was advised to remain sitting. In about twenty ininutes, the pupils being fairly but not fully dilated, the necessary exaninstion took place, H. J. H. standing daring the proceeding. A few minutes later, he experienoed a decided feeling of weakness and loss of control over the legs, great dryness of mouth, with exceedingly bitter taste. Fancying, however, the fresh air would do him good, he refused to remain, and elected to walk home. He had not gone far befure it was evident that persons in the street regarded him as decidedly "under the influence of liquor"; his speech became husky and indistinct; he walked, talked and behaved like one slightly intoxicated. Later, when at home, the syraptoms prorressed; complete inability to stand without assistance, or to recognize the position of objects, partly due, no doubt, to paralysis of accommodation, but also due to visual hallucination. For example, the patient would suddenly sit on the ground, imagining a chair was ready to receive him; drop a glass in mid.air instead of placing it on the table; and grasp in the air above his head for his watch which had been taken from him. With difficulty he was get to bed, constant attendance being necessary to keep him quiet; there was incessant movement, with carphology, a suspicious way of glancing beneath the bed-clothes and behind the back. A few moments, when left to himself, sufficed for the whole room to be upset; towels, brushes and shoes were placed in the bed, and boots on the dressing-table; this entertainment ended by a somewhat sovere fall on the floor, whence he was unablo to raise himself without assistance.

This incessant activity was accompanied by a flow of words, sen. terces strung together without any apparent connection, a return of memory to things which happened years ago; throughout, an air of fun and humour, the symptoms those of childishness rather than any attempt at violence.

The pulse was slow; the patient, entirely ignorant of what was the matter with him, imagined it was quite dark, whereas it was a bright summer afternoon. Four hours after the commencement, a small injection of morphine was giren, and the patient became quieter, dosing apparently for a few seconds at a time. Three hours later he obtained an hour's quiet sleep, and, after some light nourishment, three hours' sleep, after which his mind appeared quite clear again. He was entirely unconscious of all that had passed; a feeling of weight in the head and general upset lasted for several days. The urine, before and after, was normal. The thoughts which such a case as this gives rise to are shortly these : It is known that children bear belladonns better than adults. Do advancing years gradually increase the susceptibility? Eight cases reported biy Mr. Nettleship in 1879 would appear to indicate this. Secondly, was the poison absorbed entirely by the conjunctival mucous membrane? The bitter taste in the mouth might possibly be due to a referred sensation. Thirdly, does this susceptibility in old age point to an unpronounced pathological condition, which is liable to result, after a time, in that condition of atrophy and degeneration which is popularly known as "softening of the brain"? And, fourthly, does belladonna poisoning, which resembles so closely acute alcoholism and post-epileptic delirium in most of its symptoms, ever givo rise to those outbursts of violence -so frequently destructive to life, and so invariably succeeded by entire ignorance of a deed, perhaps of the ghastliest descriptionwhich render the medico-legal aspect of many so-called criminal cases so profoundly interesting?

\section{A CASE OF RHINOLITH.}

By AUGUSTUS F. CLAY, M.R.C.S., Casuaity surocon, Queen's Hospital, Birmingham.

NASAL calculi are so extremely rare that, so far as I can ascertain, only forty-six cases have been published since this condition was first described in the year 1502. The following case is worthy of record, especially when the size of the stone and its probablo lengthy formation are taken into consideration.

Robert F., aged 47 , married, has had an unusually healthy life, and has never suffered from rheumatism or gout. His mother informs me that when he was two years of age he was thrown from a wheclbarrow on to his face, and for many years subsequently he had an unpleasant discharge from his nose. As long as the patient himself can remember, his breath was offensive to others, and this was especially so when he cauglit cold. He has never had any difficulty in breathing. During the past two years he has complained of almost incessant frontal headache, and there has been a perceptible deviation of his nose towards the left side. When being examined, there was murked tenderness, but no local pain otherwise, and none in his ears. No discomfort bad been noticed from epiphora. There was cousiderable bulging of the right cheek and nostril, and the septum nasi was obviously deflected to the left. From a casual glance, the patient's appearance suggested that a tumour growing from the antrum had extended inwards. From the anterior nares a brown substance could be seen in the inferior meatus; and this, when examined with a probe, was found to be rough and hard. The left side was free to the passage of air; but the right was completely blocked, the mucous membrane being very much tumefied.

The patient was placed under chloroform, and an attempt was made to pass a small pair of curved polypus-forceps around the foreign body; but, until a few irregular projections had been broken off, and the stone pushed a littlo backwards, no firm hold could be maintained. Having at length got a secure grasp, by a steady traction, with slight rotatory morement, the bulk of the body was brought away, and the few remaining particles were then removed with Lister's drainageforceps. Hæmorhage was inconsiderable, and no necrosis could be detected. The nostril was syringed out three times daily with corrosive subliniate solution $(1$ in 1,000), and in a week's time the swelling of the mucous membrane had almost completely subsided. The discharge ceased; but the septum remained unaltered, although the removal of the external bulging of the nostril considerably improved the patient's general appearance.

The stone, as the accompanying woodcut shows, was shaped some-
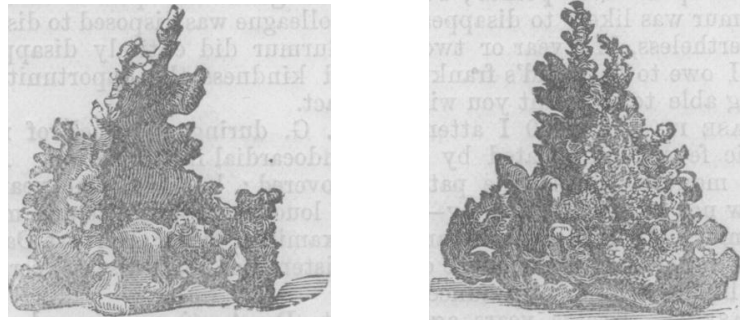

what like an isosceles triangle, the surface being particularly irregular. The length of the stone was one inch and a half; the base a little less. The weight, when dried, was 110 grains. On cutting into its base, the stone had every appearance of having originated around a cherry-stone, although only half its shell remained, and that was much altered in its physical characters.

The history of the fall from the wheelbarrow is interesting, inasmuch as it was the cause of attention being drawn to the discharge from the nose, which, in my mind, was evidently due to the introduction of the cherry-stone some time prior to the accident.

\section{NOTE ON THE CUltivation OF BaCILlUS ANTHRACIS.}

By HENRY TOMKINS, M.D., B.Sc. San. Scr. Dip., Medical Oflicer of Health, Leicester.

IN the month of July last an outbreak of splenic fever, in a village a few miles from the borough of Leicester, afforded me an opportunity of making some cultivations of the bacillus anthracis. In addition to the loss of a number of cattle, several men-butchers, labourers, and others, having the handling of the carcasses-became infected, and one man lost his life therefrom.

By the kindness of Dr. $\Lambda$. Moore, officer of health for the county, I was enabled to obtain some of the fluid from the pustules of a patient suffering from the disease. At the time this was taken, the man was beginning to convalesce, and had passed the acute stage. A drop of this fluid examined and stained showed bacilli present in scanty numbers, mixed with a number of ordinary micrococci. Cultivations were made both in a tube and on plates. In the first series the bacillus anthracis was present in fair number, but the micrococcus was still more abundant. In the second sories of cultivations made from the first, the bacilli were much diminished in number, whilst the micrococci were proportionately increased. And in the third series of cultivations the bacillus anthrax had quite disappeared, the whole growth apparently being taken up by the micrococcus. From this it would seem that the bacillus anthracis, when cultivated, may under certain conditions be killed or choked off, as it were, by another microorganism, the one in this case probably being the ordinary micrococcus met with in suppuration.

The origin of this local outbreak has not with certainty been ascer- 